\title{
Correlation of Triiodothyronine Level with In-Hospital Cardiac Function and Long-Term Prognosis in Patients with Acute Myocardial Infarction
}

\author{
Jianqing She,, Jiahao Feng, ${ }^{1,2}$ Yangyang Deng, ${ }^{1,2}$ Lizhe Sun, ${ }^{1,2}$ Yue Wu, ${ }^{1,2}$ Manyun Guo, ${ }^{1,2}$ \\ Xiao Liang, ${ }^{1,2}$ Jingjin Li, ${ }^{1,2}$ Yulong Xia, ${ }^{3}$ and Zuyi Yuan $\mathbb{D}^{1,2}$ \\ ${ }^{1}$ Cardiovascular Department, First Affiliated Hospital of Medical College, Xi'an Jiaotong University, Xi'an 710048, China \\ ${ }^{2}$ Key Laboratory of Environment and Genes Related to Diseases, Ministry of Education, Xi'an 710048, China \\ ${ }^{3}$ Cardiovascular Department, First Affiliated Hospital of Peking University, Beijing 100005, China \\ Correspondence should be addressed to Zuyi Yuan; sbw_514@163.com
}

Received 29 March 2018; Revised 20 July 2018; Accepted 30 August 2018; Published 2 December 2018

Academic Editor: Yvan Devaux

Copyright (c) 2018 Jianqing She et al. This is an open access article distributed under the Creative Commons Attribution License, which permits unrestricted use, distribution, and reproduction in any medium, provided the original work is properly cited.

\begin{abstract}
Objective. The pathophysiologic mechanism of how thyroid function is related to the development and prognosis of acute myocardial infarction (AMI) remains under explored, and there has been a lack of clinical investigations. In this study, we investigate the relationship between triiodothyronine (T3) level and cardiac ejection fraction (EF) as well as probrain natriuretic peptide (NT-proBNP) on admission and subsequent prognosis in AMI patients. Methods. We measured admission thyroid function, NT-proBNP, and EF by echocardiography in 345 patients diagnosed with AMI. Simple and multiregression analyses were performed to investigate the correlation between T3 level and EF as well as NT-proBNP. Major adverse cardiovascular events (MACE), including new-onset myocardial infarction, acute heart failure, and cardiac death, were documented during the follow-up. 248 participants were separated into three groups based on T3 and free triiodothyronine (FT3) levels for survival analysis during a 2-year follow-up. Results. 345 patients diagnosed with AMI were included in the initial observational analysis. 248 AMI patients were included in the follow-up survival analysis. The T3 levels were found to be significantly positively correlated with $\mathrm{EF}(R$ square $=0.042, P<0.001)$ and negatively correlated with admission NT-proBNP levels $(R$ square $=0.059$, $P<0.001)$, which is the same with the correlation between FT3 and EF $(R$ square $=0.053, P<0.001)$ and admission NT-proBNP levels $(R$ square $=0.108, P<0.001)$. Kaplan-Meier survival analysis revealed no significant difference with regard to different T3 or FT3 levels at the end of follow-up. Conclusions. T3 and FT3 levels are moderately positively correlated with cardiac function on admission in AMI patients but did not predict a long-time survival rate. Further studies are needed to explain whether longer-term follow-up would further identify the prognosis effect of T3 on MACE and all-cause mortality.
\end{abstract}

\section{Introduction}

Acute myocardial infarction (AMI) is one of the leading health-threatening diseases worldwide $[1,2]$. Although it has been well known that atherosclerosis contributes to the pathogenesis of AMI $[3,4]$, metabolism disorders including deregulated thyroid function have also been reported to play direct and indirect effects in the heart and vasculature lesions [5-7]. However, the pathophysiologic mechanism of how thyroid function is related to the development and prognosis of myocardial infarction remains under explored, and there has been a lack of clinical investigations.

Biologically active thyroid hormones include thyroxine (T4) and triiodothyronine (T3) $[8,9]$. It has been reported that thyroid hormone activity in the cardiomyocyte regulates myocardial contractility, diastolic, and systolic function. Moreover, thyroid hormones also exert profound effects on the heart and on cardiovascular hemodynamics, maintaining cardiac mass and wall stress while preserving ellipsoid left ventricular geometry $[10,11]$. 


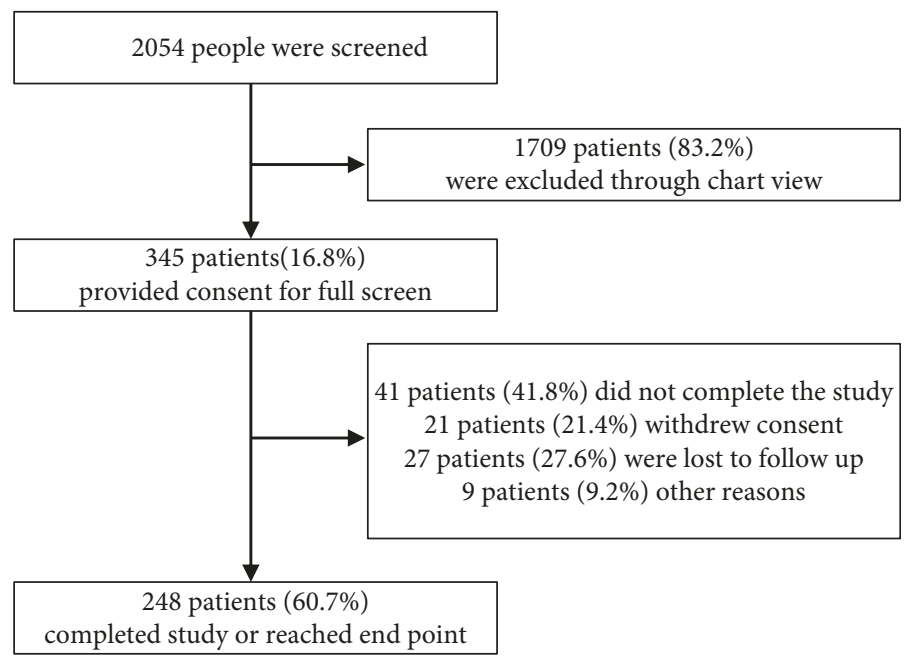

Figure 1: Enrolment and outcomes.

While T4 is solely a product of the thyroid gland, T3 is a product of the thyroid and of many other tissues. Low T3 level has been proven to be correlated with myocardial damage in animal models [12] and is associated with a poor cardiovascular prognosis in human $[11,13,14]$. Previous studies have indicated that subclinical hypothyroidism could be a predictor of adverse cardiovascular outcomes in patients with acute decompensated heart failure [14-16], and low T3 has been correlated with worse hospital outcomes in patients with acute HF $[11,14]$. However, most of the studies focused on the function of $\mathrm{T} 3$ in patients with heart failure, while there has been a lack of evidence with regard to patients with acute myocardial infarction.

In this prospective cohort study, we investigated the relationship between triiodothyronine (T3) level and cardiac ejection fraction (EF) as well as N-terminal fragment of probrain natriuretic peptide (NT-proBNP) on admission. We then carried out survival analysis to investigate the prognostic value of T3 and FT3 level on long-term mortality and morbidity in AMI patients.

\section{Research Design and Methods}

2.1. Study Design and Participants. This was a single-centre prospective cohort study. Consecutive patients admitted to the cardiology department of the First Affiliated Hospital of Xi'an Jiaotong University for AMI between January 2013 and December 2016 were selected. The inclusion criteria and exclusion criteria were as previously described [17]. AMI were defined based on the universal definition criteria by the American Cardiology College [18].

2.2. Assessment of Thyroid Function, Cardiac EF, and NTproBNP. Blood thyroid function of all patients was measured by Immulite 2000 (Bio DPC, Los Angeles, USA) within $24 \mathrm{~h}$ of admission after overnight fasting. The reference intervals of our laboratory were as follows: T3 0.78-2.20 ng/mL, T4 4.2-13.5 $\mu \mathrm{g} / \mathrm{dL}$, FT3 2.91-9.08 pmol/L, FT4 9.05-25.5 pmol/L, TSH $0.25-5 \mathrm{mIU} / \mathrm{mL}, \mathrm{TGAB}<30 \%$, and $\mathrm{TMAB}<20 \%$. The patients were further divided into 3 groups, respectively, according to tertiles of T3 and FT3. NT-proBNP levels of all patients were measured using immunoassay (Elecsys ${ }^{\circledR}$ ProBNP, Roche Diagnostics, Indianapolis, IN, USA) upon initial admission without fasting, and the reference interval was $0-125 \mathrm{pg} / \mathrm{mL}$. Because NT-proBNP values were not normally distributed, NT-proBNP levels were log-transformed to the base 2, and analyses were reported per doubling of NT-proBNP. Echocardiographs were performed on admission by experienced echo cardiologists, and systolic function was expressed as the ejection fraction (EF), which was calculated using Simpson's method.

2.3. Statistical Analysis. All statistical analyses were performed by using SPSS 17.0 for Windows (SPSS Inc., Chicago, IL). Data were presented as frequencies and percentages for categorical variables and mean $\pm \mathrm{SD}$ for continuous variables unless otherwise indicated. One-way ANOVA was used to compare continuous variables. Simple linear analysis was used for calculating correlation between T3 level and EF, T3 level and NT-proBNP, FT3 level and EF, and FT3 level and NT-proBNP, respectively. To ascertain the independent contribution to EF and NT-proBNP, multivariate regression analysis was conducted. Kaplan-Meier survival curve analysis was used to represent the proportional risk of all-cause mortality and MACE for the admission T3 and FT3 values in AMI patients. Patients were divided into three groups based on tertiles of T3 and FT3 levels. A value of $P<0.05$ was considered statistically significant.

\section{Results}

3.1. Study Population. From January 2013 till December 2016, a total of 2054 patients were enrolled in the study; 345 patients, including 139 STEMI and 206 non-STEMI patients, provided consent for full screen and were included in the initial observational analysis, while 248 patients were included in the follow-up survival analysis (Figure 1). All of 
TABLE 1: Basic characteristics based on T3 levels in AMI patients.

\begin{tabular}{|c|c|c|c|c|}
\hline & & thyronine levels ( $\mathrm{n}$ & & \\
\hline & $0.500-0.860$ & $0.862-1.140$ & $1.150-2.190$ & $P$ value \\
\hline Female (\%) & $22.02 \%$ & $24.77 \%$ & $24.77 \%$ & \\
\hline GRACE score & $112.252 \pm 42.084$ & $127.159 \pm 40.671$ & $129.294 \pm 38.054$ & $<0.01$ \\
\hline Age (y) & $58.766 \pm 10.313$ & $59.477 \pm 10.039$ & $59.725 \pm 10.237$ & 0.860 \\
\hline HR (bpm) & $70.355 \pm 21.222$ & $71.336 \pm 16.876$ & $70.706 \pm 14.019$ & 0.933 \\
\hline Onset of AMI (h) & $20.077 \pm 13.130$ & $13.538 \pm 16.033$ & $18.385 \pm 30.321$ & 0.602 \\
\hline CKMB (U/L) & $33.371 \pm 58.571$ & $48.333 \pm 70.930$ & $41.862 \pm 60.303$ & 0.210 \\
\hline HbA1C (\%) & $5.748 \pm 0.340$ & $5.744 \pm 0.361$ & $5.718 \pm 0.345$ & 0.453 \\
\hline $\mathrm{sBP}(\mathrm{mmHg})$ & $124.542 \pm 21.078$ & $126.453 \pm 16.723$ & $125.303 \pm 14.810$ & $<0.05$ \\
\hline $\mathrm{dBP}(\mathrm{mmHg})$ & $79.075 \pm 13.482$ & $78.189 \pm 10.272$ & $78.083 \pm 10.610$ & 0.061 \\
\hline $\mathrm{EF}(\%)$ & $55.059 \pm 14.298$ & $61.697 \pm 10.699$ & $61.879 \pm 11.132$ & $<0.001$ \\
\hline AST (U/L) & $77.610 \pm 79.248$ & $44.818 \pm 49.386$ & $34.039 \pm 32.576$ & $<0.001$ \\
\hline Creatine $(\mu \mathrm{mol} / \mathrm{L})$ & $69.688 \pm 16.694$ & $67.767 \pm 15.181$ & $69.090 \pm 14.364$ & 0.708 \\
\hline NT-proBNP (pg/mL) & $1561.706 \pm 3620.966$ & $552.291 \pm 758.825$ & $570.607 \pm 1117.933$ & $<0.001$ \\
\hline $\mathrm{T} 4(\mu \mathrm{g} / \mathrm{dL})$ & $6.380 \pm 1.666$ & $7.151 \pm 1.545$ & $8.053 \pm 1.808$ & $<0.001$ \\
\hline T3 (ng/mL) & $0.700 \pm 0.102$ & $1.009 \pm 0.078$ & $1.377 \pm 0.195$ & $<0.001$ \\
\hline FT4 (pmol/L) & $13.738 \pm 2.894$ & $15.028 \pm 2.991$ & $16.350 \pm 3.136$ & $<0.001$ \\
\hline FT3 (pmol/L) & $4.079 \pm 1.124$ & $4.792 \pm 1.149$ & $5.628 \pm 1.145$ & $<0.001$ \\
\hline $\mathrm{TSH}(\mu \mathrm{IU} / \mathrm{mL})$ & $2.782 \pm 7.471$ & $1.960 \pm 1.408$ & $2.748 \pm 3.519$ & 0.315 \\
\hline TGAB (\%) & $9.932 \pm 13.510$ & $6.797 \pm 9.021$ & $7.567 \pm 10.325$ & 0.117 \\
\hline TMAB (\%) & $7.295 \pm 8.741$ & $5.323 \pm 6.282$ & $5.595 \pm 6.718$ & 0.119 \\
\hline Previous history of hypertension (\%) & $47.71 \%$ & $54.13 \%$ & $52.29 \%$ & \\
\hline $\mathrm{CHF}(\%)$ & $10.09 \%$ & $7.34 \%$ & $5.50 \%$ & \\
\hline Myocardial infarction (\%) & $17.43 \%$ & $19.27 \%$ & $16.51 \%$ & \\
\hline PCI or CABG (\%) & $22.02 \%$ & $22.02 \%$ & $21.10 \%$ & \\
\hline In-hospital treatment & & & & \\
\hline Aspirin (\%) & $95.41 \%$ & $97.25 \%$ & $97.25 \%$ & \\
\hline$\beta$-Blocker (\%) & $81.65 \%$ & $88.07 \%$ & $79.82 \%$ & \\
\hline Statin $(\%)$ & $97.25 \%$ & $99.08 \%$ & $93.58 \%$ & \\
\hline CCB (\%) & $19.27 \%$ & $23.85 \%$ & $17.43 \%$ & \\
\hline
\end{tabular}

Abbreviations: GRACE: the Global Registry of Acute Coronary Events; HR: heart rate; CKMB: MB isoenzyme of creatine kinase; HbAlc: hemoglobin Alc; BP: blood pressure; EF: ejection fraction; AST: aspartate transaminase; NT-proBNP: probrain natriuretic peptide; T4: thyroxine; T3: triiodothyronine; FT4: free thyroxine; FT3: free triiodothyronine; TSH: thyroid-stimulating hormone; TGAB: thyroglobulin; TMAB: thyroid microsomal antibody; CHF: chronic heart failure; PCI: percutaneous coronary intervention; CABG: coronary artery bypass graft; CCB: calcium channel blocker. Data are mean \pm SD and number (\%),

the patients have received coronary angiography, and 95.36\% patients had coronary intervention. Patients were divided into three groups based on tertiles of $\mathrm{T} 3$ and FT3 levels for the survival analysis. Baseline patients' characteristics are shown in Table 1 based on the T3 levels $(0.500-$ $0.860 \mathrm{ng} / \mathrm{mL}, 0.862-1.140 \mathrm{ng} / \mathrm{mL}$, and $1.150-2.190 \mathrm{ng} / \mathrm{mL})$ and in Table 2 based on the FT3 levels $(1.62-3.98 \mathrm{pmol} / \mathrm{L}$, $3.99-5.33 \mathrm{pmol} / \mathrm{L}$, and $5.34-8.55 \mathrm{pmol} / \mathrm{L})$. The mean age was $58.766 \pm 10.313,59.477 \pm 10.039$, and $59.725 \pm 10.237$ years in respective T3 groups and was 59.625 \pm 10.468 , $58.351 \pm 10.107$, and $59.694 \pm 10.490$ in FT3 groups. No significant difference in risk factors at baseline was seen in different T3 and FT3 groups except for aspartate transaminase (AST), EF, NT-proBNP, and thyroid hormones.

3.2. Association between T3 and Cardiac Function. As baseline characters exhibited a significant alteration of EF and NT-proBNP based on different T3 and FT3 levels, which were crucially important to evaluate cardiac function during AMI, we then carried on to investigate the relationship between $\mathrm{T} 3$ and cardiac function by regression analysis. The T3 levels were found to be significantly positively correlated with $\mathrm{EF}(R$ square $=0.042, P<0.001)$ and negatively correlated with admission NT-proBNP levels ( $R$ square $=0.059, P<0.001)$, which is the same with the correlation between FT3 and EF $(R$ square $=0.053, P<0.001)$ and admission NT-proBNP levels ( $R$ square $=0.108, P<$ 0.001 ) (Figure 2). Multiregression analysis was then utilized to further explain the association of T3 and cardiac function. Interestingly, although both T3 and FT3 levels were found to be significantly positively correlated with EF in AMI patients $(P<0.05)$, only FT3 was found to be significantly negatively correlated with NT-proBNP $(P<0.05)$. In addition, TSH, thyroid-stimulating hormone, was also 
TABLE 2: Basic characteristics based on FT3 levels in AMI patients.

\begin{tabular}{|c|c|c|c|c|}
\hline & \multicolumn{3}{|c|}{ Free triiodothyronine levels $(\mathrm{pmol} / \mathrm{L})$} & \multirow{2}{*}{$P$ value } \\
\hline & $1.62-3.98$ & $3.99-5.33$ & $5.34-8.55$ & \\
\hline Female (\%) & $18.35 \%$ & $18.35 \%$ & $22.94 \%$ & \\
\hline GRACE score & $116.098 \pm 43.037$ & $121.991 \pm 40.497$ & $128.117 \pm 38.421$ & 0.091 \\
\hline Age $(y)$ & $59.625 \pm 10.468$ & $58.351 \pm 10.107$ & $59.694 \pm 10.490$ & 0.550 \\
\hline $\mathrm{HR}(\mathrm{bpm})$ & $69.732 \pm 14.248$ & $72.728 \pm 22.362$ & $69.856 \pm 13.955$ & 0.344 \\
\hline Onset of AMI (h) & $17.538 \pm 32.545$ & $17.769 \pm 30.339$ & $16.692 \pm 18.481$ & 0.911 \\
\hline CKMB (U/L) & $40.333 \pm 66.052$ & $40.266 \pm 61.909$ & $41.398 \pm 60.269$ & 0.989 \\
\hline HbA1C (\%) & $124.027 \pm 19.070$ & $124.513 \pm 18.211$ & $125.973 \pm 16.001$ & 0.272 \\
\hline $\mathrm{sBP}(\mathrm{mmHg})$ & $76.929 \pm 11.943$ & $78.796 \pm 11.498$ & $78.369 \pm 11.353$ & 0.700 \\
\hline $\mathrm{dBP}(\mathrm{mmHg})$ & $5.693 \pm 0.356$ & $5.744 \pm 0.357$ & $5.767 \pm 0.328$ & 0.454 \\
\hline $\mathrm{EF}(\%)$ & $67.939 \pm 14.945$ & $69.152 \pm 16.936$ & $69.203 \pm 14.298$ & $<0.001$ \\
\hline AST (U/L) & $55.486 \pm 13.468$ & $60.057 \pm 11.187$ & $62.135 \pm 11.974$ & $<0.05$ \\
\hline Creatine $(\mu \mathrm{mol} / \mathrm{L})$ & $68.437 \pm 75.677$ & $53.158 \pm 57.580$ & $40.438 \pm 45.711$ & 0.192 \\
\hline NT-proBNP (pg/mL) & $1780.395 \pm 3700.982$ & $739.469 \pm 1208.398$ & $411.908 \pm 537.265$ & $<0.001$ \\
\hline $\mathrm{T} 4(\mu \mathrm{g} / \mathrm{dL})$ & $6.464 \pm 1.641$ & $7.005 \pm 1.687$ & $7.911 \pm 1.875$ & $<0.001$ \\
\hline T3 (ng/mL) & $0.845 \pm 0.238$ & $1.015 \pm 0.277$ & $1.218 \pm 0.286$ & $<0.001$ \\
\hline FT4 (pmol/L) & $13.432 \pm 2.918$ & $14.832 \pm 2.836$ & $16.540 \pm 3.075$ & $<0.001$ \\
\hline FT3 (pmol/L) & $3.336 \pm 0.512$ & $4.690 \pm 0.394$ & $6.295 \pm 0.750$ & $<0.001$ \\
\hline $\mathrm{TSH}(\mu \mathrm{IU} / \mathrm{mL})$ & $2.812 \pm 7.305$ & $2.238 \pm 3.348$ & $2.241 \pm 1.618$ & 0.585 \\
\hline TGAB (\%) & $8.873 \pm 12.438$ & $6.765 \pm 9.865$ & $8.271 \pm 10.397$ & 0.335 \\
\hline TMAB (\%) & $6.567 \pm 8.205$ & $5.184 \pm 6.313$ & $6.202 \pm 7.025$ & 335.000 \\
\hline Previous history of hypertension (\%) & $44.95 \%$ & $50.46 \%$ & $54.13 \%$ & \\
\hline $\mathrm{CHF}(\%)$ & $6.42 \%$ & $1.83 \%$ & $1.83 \%$ & \\
\hline Myocardial infarction (\%) PCI or CABG (\%) & $13.76 \%$ & $13.76 \%$ & $14.68 \%$ & \\
\hline In-hospital treatment & $18.35 \%$ & $16.51 \%$ & $20.18 \%$ & \\
\hline Aspirin (\%) & $95.41 \%$ & $97.25 \%$ & $97.25 \%$ & \\
\hline$\beta$-Blocker (\%) & $78.90 \%$ & $88.99 \%$ & $80.73 \%$ & \\
\hline Statin $(\%)$ & $97.25 \%$ & $99.08 \%$ & $92.66 \%$ & \\
\hline CCB (\%) & $15.60 \%$ & $19.27 \%$ & $15.60 \%$ & \\
\hline
\end{tabular}

Abbreviations: GRACE: the Global Registry of Acute Coronary Events; HR: heart rate; CKMB: MB isoenzyme of creatine kinase; HbAlc: hemoglobin A1c; BP: blood pressure; EF: ejection fraction; AST: aspartate transaminase; NT-proBNP: probrain natriuretic peptide; T4: thyroxine; T3: triiodothyronine; FT4: free thyroxine; FT3: free triiodothyronine; TSH: thyroid-stimulating hormone; TGAB: thyroglobulin; TMAB: thyroid microsomal antibody; CHF: chronic heart failure; PCI: percutaneous coronary intervention; CABG: coronary artery bypass graft; CCB: calcium channel blocker. Data are mean \pm SD and number (\%).

found to be positively correlated with $\mathrm{EF} \quad(P<0.05)$ (Table 3). It is noteworthy that the TSH, T4, and FT4 did not exhibit a significant correlation with cardiac function in the present cohort.

3.3. All-Cause Mortality and MACE. During the follow-up period, $12(5.2 \%)$ patients died for all cause, 9 (4.0\%) for cardiac cause, 28 (11.6\%) for acute heart failure, and 12 (4.4\%) had new-onset myocardial infarction. We also examined the prognostic significance of T3 and FT3 in AMI. As demonstrated in the Kaplan-Meier plots, the analysis revealed no significant difference with regard to different T3 or FT3 levels, as shown in Figure 3.

\section{Discussion}

In this study, serum FT3 level was found to be moderately associated with the cardiac function, as indicated by EF and
NT-proBNP levels, on admission in patients with acute myocardial infarction. However, neither T3 nor FT3 exhibited effects on all-cause mortality rate and MACE in AMI patients during 2-year follow-up.

The important implication of the present study is that T3 levels are found to be correlated with the cardiac function as indicated by EF and NT-proBNP in AMI patients. In vitro studies have shown that $\mathrm{T} 3$ activates and regulates cardiac genes encoding proteins such as the myosin heavy chain isoforms and the sarcoplasmic reticulum calcium-activated ATPase pump [19-21], indicating a possible relationship between T3 level and cardiac function. Previous study has also indicated that $\mathrm{T} 3$ predicts outcomes in patients with acute heart failure [11]. In addition, low $\mathrm{T} 3$ is found out to be associated with elevation of $\mathrm{N}$-terminal probrain natriuretic peptide (NT-proBNP) and mortality in dialysis patients [13, 22, 23]. However, few studies have addressed the question whether thyroid function is related to cardiac 


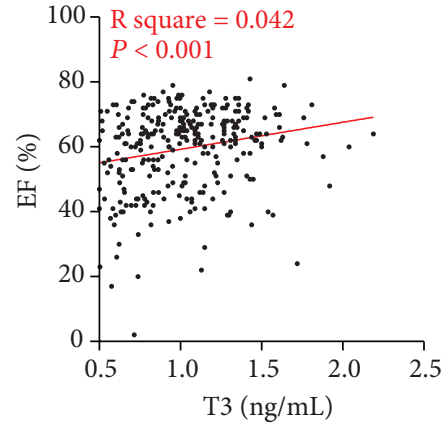

(a)

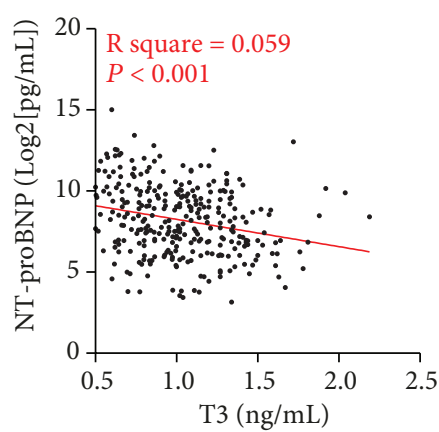

(c)

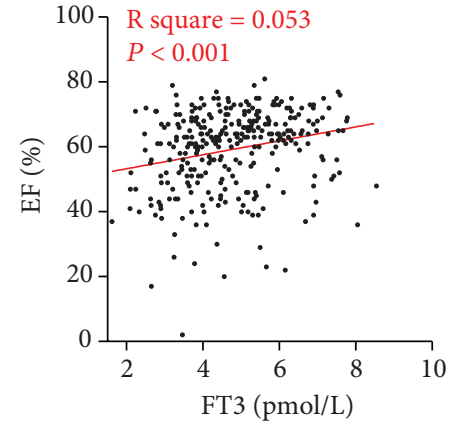

(b)

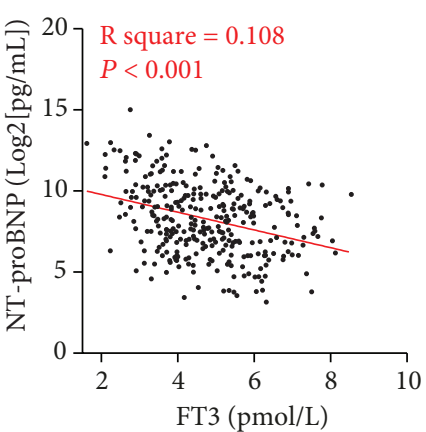

(d)

FIGURE 2: Linear analysis between heart function and triiodothyronine level. (a) Simple linear regression model with heart ejection fraction in relation to triiodothyronine level. (b) Simple linear regression model with heart ejection fraction in relation to free triiodothyronine level. (c) Simple linear regression model with NT-proBNP in relation to triiodothyronine level. (d) Simple linear regression model with NT-proBNP in relation to free triiodothyronine level.

TABLE 3: Multiregression analysis of NT-proBNP and EF.

\begin{tabular}{|c|c|c|c|}
\hline Factors & Coefficient & SEM & $P$ value \\
\hline \multicolumn{4}{|c|}{$\begin{array}{l}\text { Multiregression analysis of } \\
\text { NT-proBNP }\end{array}$} \\
\hline Age (y) & -0.001 & 14.246 & 0.994 \\
\hline HR (bpm) & 0.161 & 7.271 & $<0.05$ \\
\hline GRACE score & 0.106 & 3.986 & 0.141 \\
\hline T3 (ng/mL) & -0.094 & 486.295 & 0.155 \\
\hline FT3 (pmol/L) & -0.195 & 115.569 & $<0.05$ \\
\hline $\mathrm{TSH}(\mu \mathrm{IU} / \mathrm{mL})$ & -0.024 & 25.870 & 0.666 \\
\hline CKMB (U/L) & -0.045 & 2.294 & 0.480 \\
\hline Creatine $(\mu \mathrm{mol} / \mathrm{L})$ & 0.014 & 8.706 & 0.807 \\
\hline HbA1C (\%) & -0.039 & 377.367 & 0.495 \\
\hline \multicolumn{4}{|c|}{ Multiregression analysis of EF } \\
\hline Age (y) & -0.051 & 0.081 & 0.432 \\
\hline $\mathrm{HR}(\mathrm{bpm})$ & 0.087 & 0.041 & 0.134 \\
\hline GRACE score & 0.017 & 0.023 & 0.816 \\
\hline T3 (ng/mL) & 0.132 & 2.687 & $<0.05$ \\
\hline FT3 (pmol/L) & 0.152 & 0.633 & $<0.05$ \\
\hline $\mathrm{TSH}(\mu \mathrm{IU} / \mathrm{mL})$ & 0.121 & 0.145 & $<0.05$ \\
\hline CKMB (U/L) & 0.021 & 0.013 & 0.744 \\
\hline Creatine $(\mu \mathrm{mol} / \mathrm{L})$ & -0.117 & 0.052 & 0.054 \\
\hline HbA1C (\%) & 0.034 & 2.126 & 0.564 \\
\hline
\end{tabular}

Abbreviations: HR: heart rate; GRACE: the Global Registry of Acute Coronary Events; T3: triiodothyronine; FT3: free triiodothyronine; TSH: thyroid-stimulating hormone; CKMB: $\mathrm{MB}$ isoenzyme of creatine kinase; HbAlc: hemoglobin Alc. function during acute myocardial infarction. The major outcome of this study shows a positive correlation between T3 and FT3 levels and cardiac ejection fraction, indicating that T3 level is a potential therapeutic target for cardiac function improvement during acute myocardial infarction.

In the present analysis, it is noteworthy that the TSH, T4, and FT4 did not exhibit a significant correlation. The results correlate with previous publications that low T3 level has been proven to be correlated with myocardial damage in animal models. It has been known that T4 is solely a product of the thyroid gland, while T3 is a product of the thyroid and of many other tissues. Thus, the difference in the correlation results among thyroid hormones might reflect differential thyroid metabolism and function in AMI patients and requires further mechanism investigation.

Our study also shows that T3 and FT3 levels do not predict adverse cardiovascular outcomes in AMI patients. There is conflicting evidence regarding thyroid hormone levels and cardiovascular outcomes [24-26]. It has been reported that thyroid function tests predict disability in advanced old age patients, with higher serum TSH levels predicting better outcomes [27]. Moreover, in patients with acute heart failure, subclinical hypothyroidism on admission is an independent predictor of adverse cardiovascular outcomes [24]. In this study, thyroid function is not associated with all-cause mortality and MACE in AMI patients over a 2-year followup, indicating that the interaction between $\mathrm{T} 3$ and cardiac function might be more significant during acute phase of myocardial infarction. Meanwhile, it is also noteworthy that 
T3

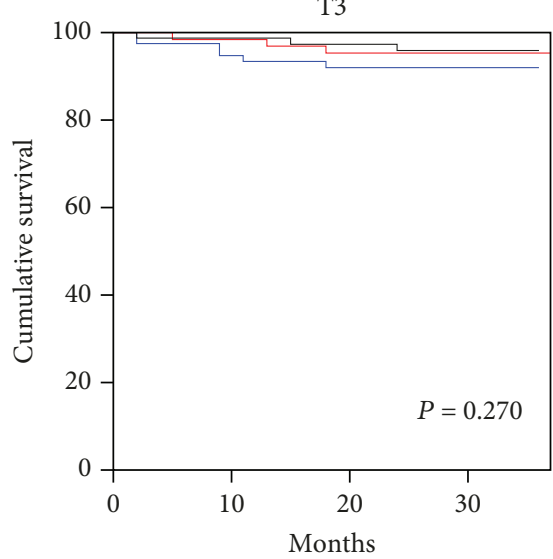

T3 levels (ng/mL)
$-0.500-0.860$
$-0.862-1.140$
$-1.150-2.190$

(a)

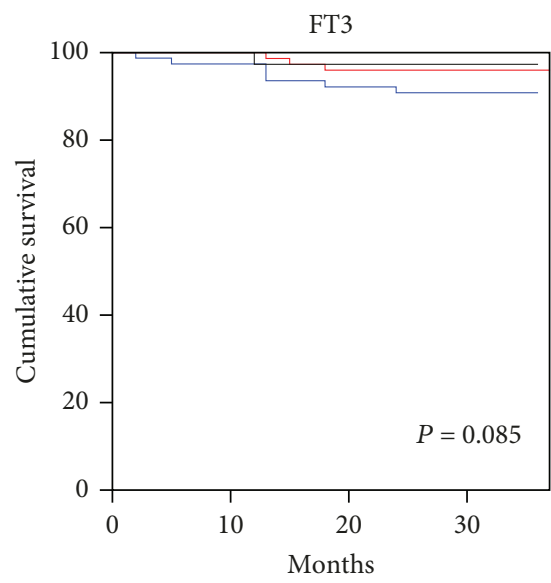

FT3 levels $(\mathrm{pmol} / \mathrm{L})$

$1.62-3.98$
$-\quad 3.99-5.33$
$-5.34-8.55$

(c)

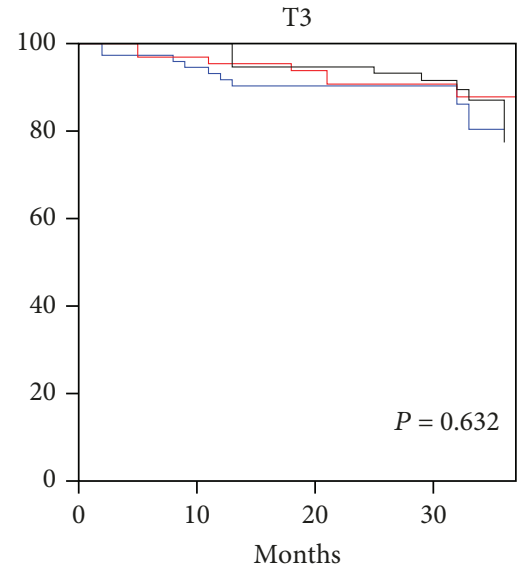

T3 levels (ng/mL)

- 0.500-0.860

- 0.862-1.140

- 1.150-2.190

(b)

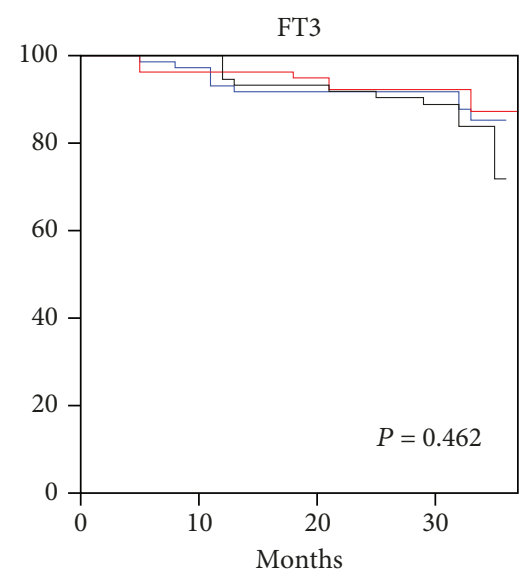

FT3 levels $(\mathrm{pmol} / \mathrm{L})$

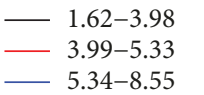

(d)

Figure 3: Kaplan-Meier survival curves for freedom from all-cause mortality and MACE judging by triiodothyronine level. (a) Kaplan-Meier survival curve for freedom from all-cause mortality judging by triiodothyronine level. $P=0.270$. (b) Kaplan-Meier survival curves for freedom from MACE judging by triiodothyronine level. $P=0.632$. (c) Kaplan-Meier survival curves for freedom from all-cause mortality judging by free triiodothyronine level. $P=0.085$. (d) Kaplan-Meier survival curves for freedom from MACE judging by free triiodothyronine level. $P=0.462$. There is no significantly higher event-free survival rate in high triiodothyronine and free triiodothyronine levels.

the less clear association between $\mathrm{T} 3$ and cardiovascular outcomes could be due to a limited number of patients with a relatively short follow-up in the present study, and its association with long-term prognosis may be stronger. As a result, more well-designed and long-term studies as well as systemic analysis are needed to investigate whether thyroid function will play an important role in the prognosis of AMI.

The present study also has several limitations. On the one hand, this is a single-centre-based observational cohort study. As the sample size in this study is relatively small, thus, the comparisons of subgroups may lack power to detect significant differences for selected variables, especially in Kaplan-Meier survival analysis. Notably, the association between $\mathrm{T} 3$ levels and cardiac function as interpreted by EF and NT-proBNP exhibits only low correlation coefficients, indicating at best a moderate association. On the other hand, the onset of AMI and the coronary intervention vary among patients. As a result, the correlation between AMI progression, iodine intake, and thyroid function could lead to a confounding bias and limit the interpretation of pathophysiology of thyroid function during the onset and progression of AMI. Therefore, multicentre-based clinical observations and subgroup analysis are necessary to further evaluate the predictive value of T3 for MACE and all-cause mortality, so as to explore the therapeutic value of modulating thyroid function during AMI. 
In conclusion, in patients with AMI, T3 and FT3 levels are moderately positively correlated with cardiac function on admission in AMI patients but did not predict a longtime survival rate. The results of this study further provide therapeutic view that thyroid function control could be one of the treatment targets for AMI patients. Further studies are needed to determine whether longer-term follow-up would further identify the prognosis effect of T3 on MACE and all-cause mortality.

$\begin{array}{ll}\text { Abbreviations } \\ \text { AMI: } & \text { Acute myocardial infarction } \\ \text { T3: } & \text { Triiodothyronine } \\ \text { FT3: } & \text { Free triiodothyronine } \\ \text { T4: } & \text { Thyroxine } \\ \text { FT4: } & \text { Free thyroxine } \\ \text { TSH: } & \text { Thyroid-stimulating hormone } \\ \text { TGAB: } & \text { Thyroglobulin } \\ \text { TMAB: } & \text { Thyroid microsomal antibody } \\ \text { EF: } & \text { Cardiac ejection fraction } \\ \text { NT-proBNP: } & \text { N-terminal probrain natriuretic peptide } \\ \text { MACE: } & \text { Major adverse cardiovascular events } \\ \text { GRACE: } & \text { The Global Registry of Acute Coronary Events } \\ \text { HR: } & \text { Heart rate } \\ \text { CKMB: } & \text { MB isoenzyme of creatine kinase } \\ \text { HbA1c: } & \text { Hemoglobin Alc } \\ \text { BP: } & \text { Blood pressure } \\ \text { AST: } & \text { Aspartate transaminase } \\ \text { CHF: } & \text { Chronic heart failure } \\ \text { PCI: } & \text { Percutaneous coronary intervention } \\ \text { CABG: } & \text { Coronary artery bypass graft } \\ \text { CCB: } & \text { Calcium channel blocker. }\end{array}$

\section{Data Availability}

The datasets analysed during the current study are available from the corresponding author on reasonable request.

\section{Ethical Approval}

This study was approved by the ethics committee of the First Affiliated Hospital of Xi' an Jiaotong University.

\section{Consent}

Written informed consent was obtained from all study participants.

\section{Conflicts of Interest}

The authors declare that they have no conflicts of interest.

\section{Authors' Contributions}

All listed authors have contributed significantly to the research and manuscript. JS, JF, YW, and ZY participated in the design of the study. YD and LS collected the written informed consent and patients' data. LS and YX performed the statistical analysis. JS and JF drafted the manuscript. All authors approved the final manuscript. Jianqing She, Jiahao Feng, and Yangyang Deng contributed equally to this work.

\section{Acknowledgments}

The authors acknowledge the support of China Scholarship Council (CSC) and Deutscher Akademischer Austauschdienst (DAAD). This study was also supported by the Central University Basic Science Foundation of China (1191329724), the National Natural Science Foundation of China (81570406, 81800390), and the Natural Science Foundation of Shaanxi Province (2018KW067).

\section{References}

[1] J. She, Z. Hu, Y. Deng, F. Liu, and Z. Yuan, "Chest pain after aortic valve replacement: rupture of right sinus of Valsalva presenting as myocardial infarction," Cardiology, vol. 134, no. 1, pp. 22-25, 2016.

[2] J. E. Hollander, M. Than, and C. Mueller, "State-of-the-art evaluation of emergency department patients presenting with potential acute coronary syndromes," Circulation, vol. 134, no. 7, pp. 547-564, 2016.

[3] S. T. Vernon, S. Coffey, R. Bhindi et al., "Increasing proportion of ST elevation myocardial infarction patients with coronary atherosclerosis poorly explained by standard modifiable risk factors," European Journal of Preventive Cardiology, vol. 24, no. 17, pp. 1824-1830, 2017.

[4] S. K. Kidd, M. P. Bonaca, E. Braunwald et al., "Universal classification system type of incident myocardial infarction in patients with stable atherosclerosis: observations from thrombin receptor antagonist in secondary prevention of atherothrombotic ischemic events (TRA $2^{\circ} \mathrm{P}$ )-TIMI 50," Journal of the American Heart Association, vol. 5, no. 7, 2016.

[5] S. S. Martin, N. Daya, P. L. Lutsey et al., "Thyroid function, cardiovascular risk factors, and incident atherosclerotic cardiovascular disease: the Atherosclerosis Risk in Communities (ARIC) Study," The Journal of Clinical Endocrinology and Metabolism, vol. 102, no. 9, pp. 3306-3315, 2017.

[6] Y. Ling, J. Jiang, M. Gui et al., "Thyroid function, prevalent coronary heart disease, and severity of coronary atherosclerosis in patients undergoing coronary angiography," International Journal of Endocrinology, vol. 2015, Article ID 708272, 9 pages, 2015.

[7] W. Wang, H. Guan, A. M. Gerdes, G. Iervasi, Y. Yang, and Y. D. Tang, "Thyroid status, cardiac function, and mortality in patients with idiopathic dilated cardiomyopathy," The Journal of Clinical Endocrinology and Metabolism, vol. 100, no. 8, pp. 3210-3218, 2015.

[8] G. Hennemann, R. Docter, E. C. H. Friesema, M. de Jong, E. P. Krenning, and T. J. Visser, "Plasma membrane transport of thyroid hormones and its role in thyroid hormone metabolism and bioavailability," Endocrine Reviews, vol. 22, no. 4, pp. 451-476, 2001.

[9] Y. C. Chen, S. A. Chen, Y. J. Chen, M. S. Chang, P. Chan, and C. I. Lin, "Effects of thyroid hormone on the arrhythmogenic activity of pulmonary vein cardiomyocytes," Journal of the American College of Cardiology, vol. 39, no. 2, pp. 366-372, 2002.

[10] W. Wang, H. Guan, W. Fang et al., "Free triiodothyronine level correlates with myocardial injury and prognosis in idiopathic 
dilated cardiomyopathy: evidence from cardiac MRI and SPECT/PET imaging," Scientific Reports, vol. 6, no. 1, article 39811, 2016.

[11] G. D. Rothberger, S. Gadhvi, N. Michelakis, A. Kumar, R. Calixte, and L. E. Shapiro, "Usefulness of serum triiodothyronine (T3) to predict outcomes in patients hospitalized with acute heart failure," The American Journal of Cardiology, vol. 119, no. 4, pp. 599-603, 2017.

[12] T. E. Lehnen, M. V. Santos, A. Lima, A. L. Maia, and S. M. Wajner, "N-acetylcysteine prevents low T3 syndrome and attenuates cardiac dysfunction in a male rat model of myocardial infarction," Endocrinology, vol. 158, no. 5, pp. 1502-1510, 2017.

[13] M. d. C. Prado-Uribe, M.-d.-J. Ventura, M. Ávila-Díaz et al., "Low triiodothyronine is associated with elevation of $\mathrm{N}$ terminal pro-brain natriuretic peptide (NT-proBNP) and mortality in dialysis patients," Nefrología, vol. 37 , no. 6 , pp. 598-607, 2017.

[14] T. Hayashi, T. Hasegawa, H. Kanzaki et al., "Subclinical hypothyroidism is an independent predictor of adverse cardiovascular outcomes in patients with acute decompensated heart failure," ESC Heart Failure, vol. 3, no. 3, pp. 168-176, 2016.

[15] D. Okayama, Y. Minami, S. Kataoka, T. Shiga, and N. Hagiwara, "Thyroid function on admission and outcome in patients hospitalized for acute decompensated heart failure," Journal of Cardiology, vol. 66, no. 3, pp. 205-211, 2015.

[16] M. E. Ziman, H. T. Bui, C. S. Smith et al., “The pharmacists' role in improving guideline compliance for thyroid function testing in patients with heart failure," Journal of Pharmacy Practice, vol. 25, no. 2, pp. 195-200, 2012.

[17] J. She, Y. Deng, Y. Wu et al., "Hemoglobin $A_{1 c}$ is associated with severity of coronary artery stenosis but not with long term clinical outcomes in diabetic and nondiabetic patients with acute myocardial infarction undergoing primary angioplasty," Cardiovascular Diabetology, vol. 16, no. 1, p. 97, 2017.

[18] G. N. Levine, E. R. Bates, J. A. Bittl et al., "2016 ACC/AHA guideline focused update on duration of dual antiplatelet therapy in patients with coronary artery disease: a report of the American College of Cardiology/American Heart Association Task Force on clinical practice guidelines: an update of the $2011 \mathrm{ACCF} / \mathrm{AHA} / \mathrm{SCAI}$ guideline for percutaneous coronary intervention, $2011 \mathrm{ACCF} / \mathrm{AHA}$ guideline for coronary artery bypass graft surgery, 2012 ACC/AHA/ACP/AATS/PCNA/ SCAI/STS guideline for the diagnosis and management of patients with stable ischemic heart disease, 2013 ACCF/AHA guideline for the management of ST-elevation myocardial infarction, 2014 AHA/ACC guideline for the management of patients with non-ST-elevation acute coronary syndromes, and 2014 ACC/AHA guideline on perioperative cardiovascular evaluation and management of patients undergoing noncardiac surgery," Circulation, vol. 134, no. 10, pp. e123-e155, 2016.

[19] W. Mai, M. F. Janier, N. Allioli et al., "Thyroid hormone receptor alpha is a molecular switch of cardiac function between fetal and postnatal life," Proceedings of the National Academy of Sciences of the United States of America, vol. 101, no. 28, pp. 10332-10337, 2004.

[20] E. A. Swanson, B. Gloss, D. D. Belke, M. Kaneshige, S. Y. Cheng, and W. H. Dillmann, "Cardiac expression and function of thyroid hormone receptor $\beta$ and its PV mutant," Endocrinology, vol. 144, no. 11, pp. 4820-4825, 2003.
[21] K. Ojamaa, A. Kenessey, and I. Klein, "Thyroid hormone regulation of phospholamban phosphorylation in the rat heart," Endocrinology, vol. 141, no. 6, pp. 2139-2144, 2000.

[22] M. Pinelli, M. Bindi, G. Cassetti et al., "Relationship between low T3 syndrome and NT-proBNP levels in non-cardiac patients," Acta Cardiologica, vol. 62, no. 1, pp. 19-24, 2007.

[23] C. P. Chuang, Y. S. Jong, C. Y. Wu, and H. M. Lo, "Impact of triiodothyronine and $\mathrm{N}$-terminal pro-B-type natriuretic peptide on the long-term survival of critically ill patients with acute heart failure," The American Journal of Cardiology, vol. 113, no. 5, pp. 845-850, 2014.

[24] A. Altamirano Ufion, B. Zulfiqar, A. Hassan, R. Habibi, and P. Boddu, "Subclinical hypothyroidism and its association with increased cardiovascular mortality," Cardiology Research and Practice, vol. 2017, Article ID 7539735, 5 pages, 2017.

[25] A. Bano, L. Chaker, F. U. S. Mattace-Raso et al., "Thyroid function and the risk of atherosclerotic cardiovascular morbidity and mortality: the Rotterdam Study," Circulation Research, vol. 121, no. 12, pp. 1392-1400, 2017.

[26] D. J. Stott, J. Gussekloo, P. M. Kearney et al., "Study protocol; thyroid hormone replacement for untreated older adults with subclinical hypothyroidism - a randomised placebo controlled trial (TRUST)," BMC Endocrine Disorders, vol. 17, no. 1, p. 6, 2017.

[27] S. H. S. Pearce, S. Razvi, M. E. Yadegarfar et al., "Serum thyroid function, mortality and disability in advanced old age: the Newcastle 85+ study," The Journal of Clinical Endocrinology and Metabolism, vol. 101, no. 11, pp. 4385-4394, 2016. 


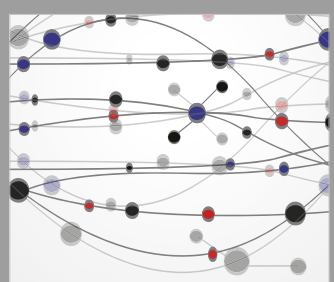

The Scientific World Journal
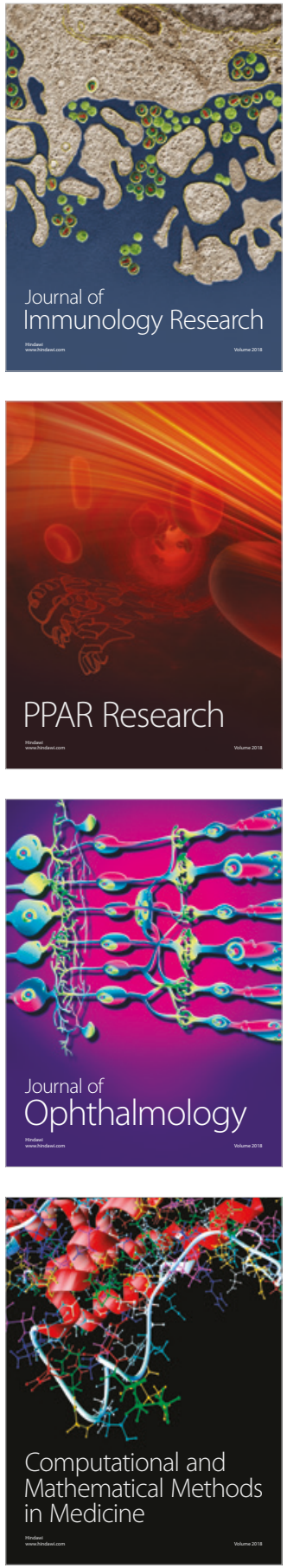

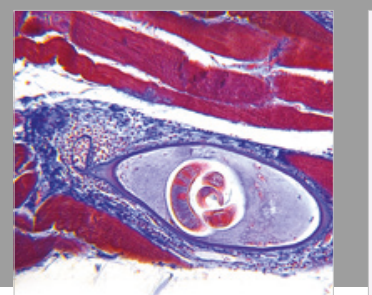

Gastroenterology Research and Practice

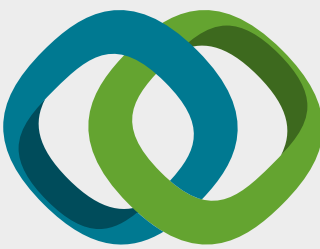

\section{Hindawi}

Submit your manuscripts at

www.hindawi.com
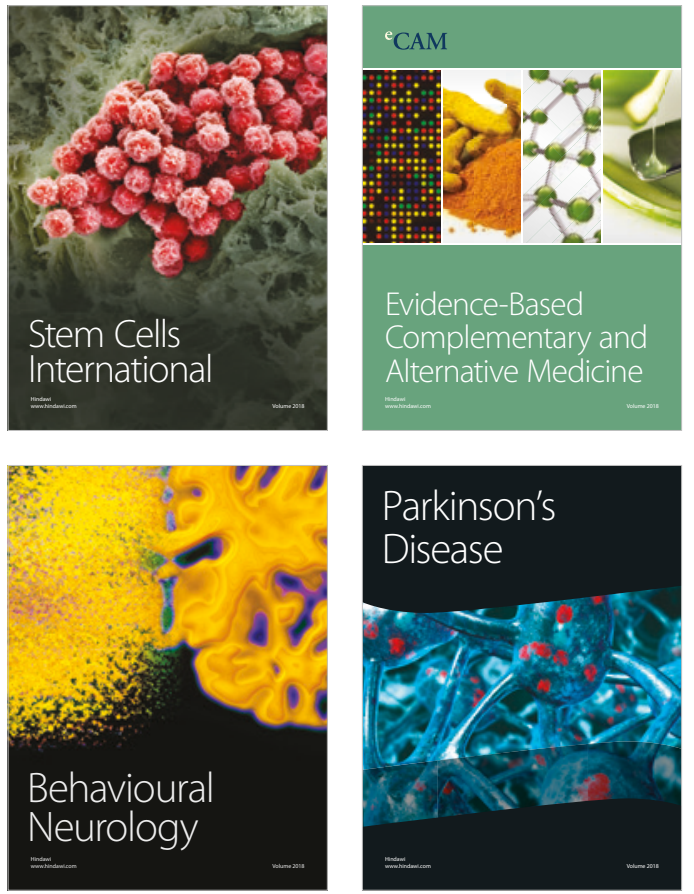

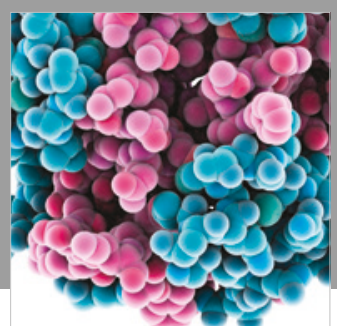

ournal of

Diabetes Research

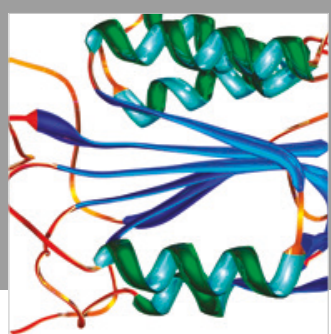

Disease Markers
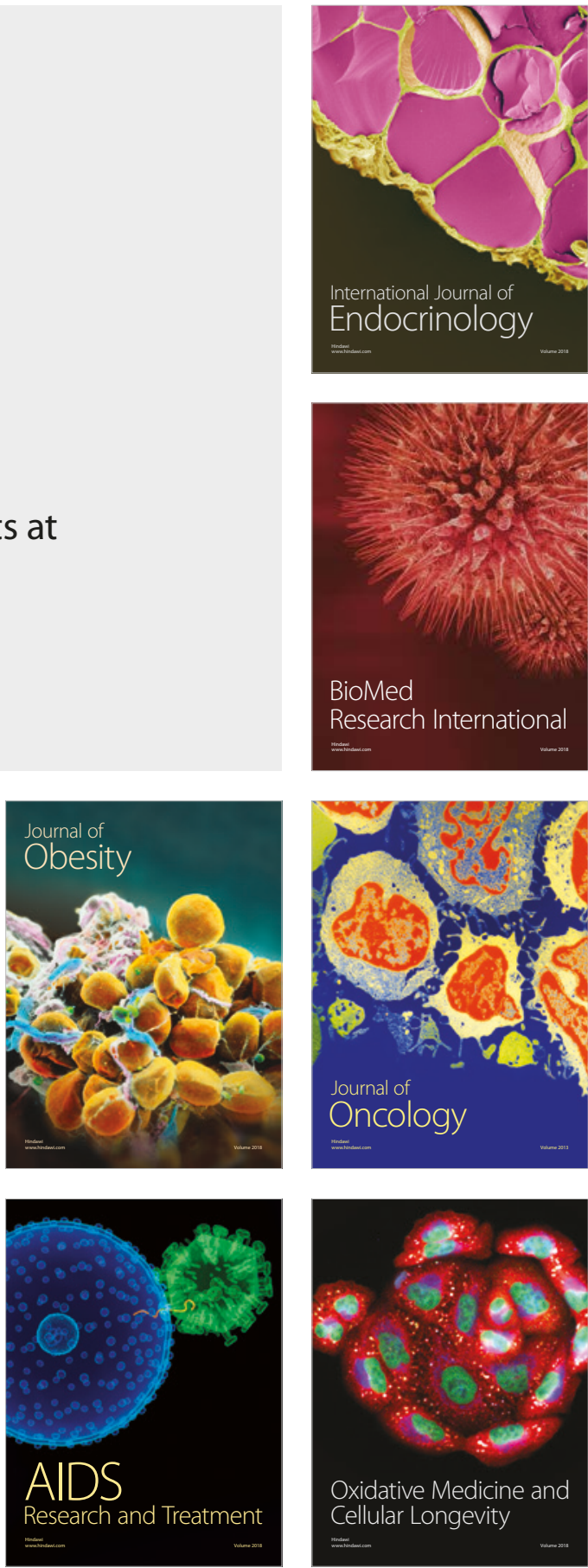